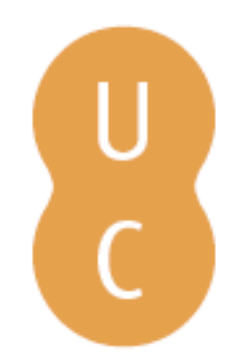

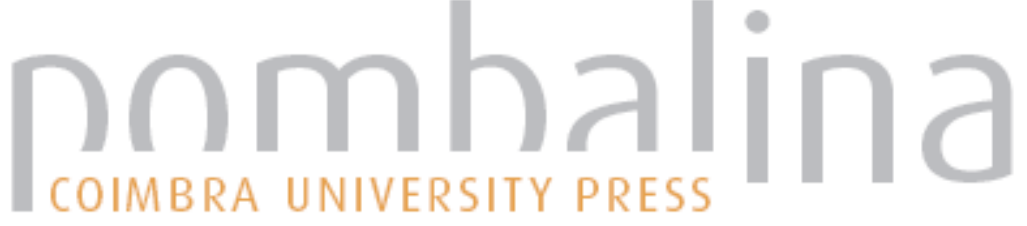

\section{Lo pastoril en el teatro de Gil Vicente}

Autor(es): $\quad$ Rodríguez Rodríguez, José Javier

Publicado por: Imprensa da Universidade de Coimbra

URL

persistente: URI:http://hdl.handle.net/10316.2/47471

DOI: $\quad$ DOl:https://doi.org/10.14195/978-989-26-1548-6_9

Accessed : $\quad$ 26-Apr-2023 10:30:16

A navegação consulta e descarregamento dos títulos inseridos nas Bibliotecas Digitais UC Digitalis, UC Pombalina e UC Impactum, pressupõem a aceitação plena e sem reservas dos Termos e Condições de Uso destas Bibliotecas Digitais, disponíveis em https://digitalis.uc.pt/pt-pt/termos.

Conforme exposto nos referidos Termos e Condições de Uso, o descarregamento de títulos de acesso restrito requer uma licença válida de autorização devendo o utilizador aceder ao(s) documento(s) a partir de um endereço de IP da instituição detentora da supramencionada licença.

Ao utilizador é apenas permitido o descarregamento para uso pessoal, pelo que o emprego do(s) título(s) descarregado(s) para outro fim, designadamente comercial, carece de autorização do respetivo autor ou editor da obra.

Na medida em que todas as obras da UC Digitalis se encontram protegidas pelo Código do Direito de Autor e Direitos Conexos e demais legislação aplicável, toda a cópia, parcial ou total, deste documento, nos casos em que é legalmente admitida, deverá conter ou fazer-se acompanhar por este aviso.

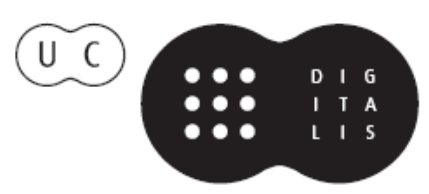



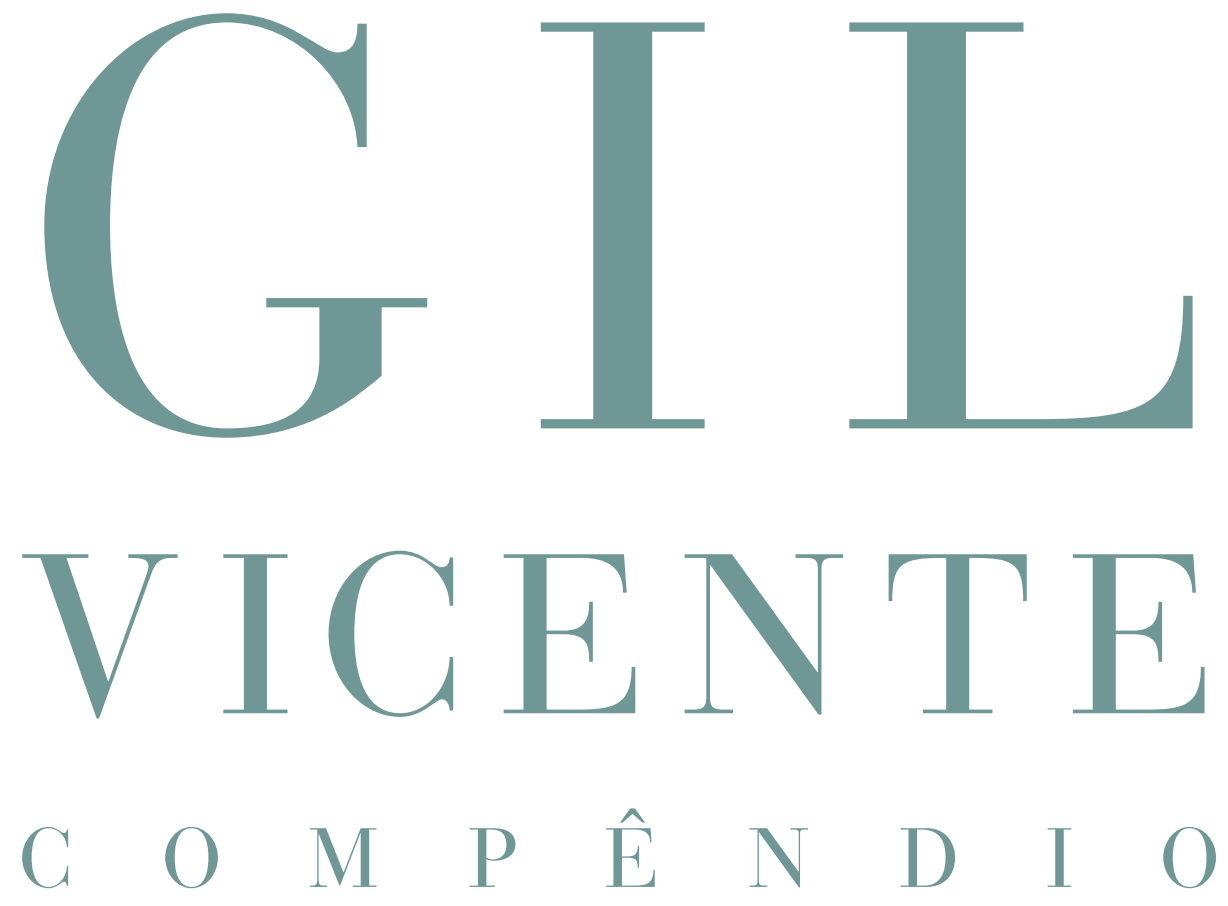

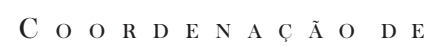

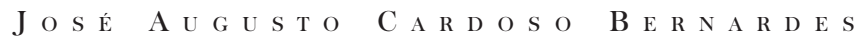

E J O S É C A M Õ E S

CoimbraCompanions

IVPRENSA DA UNIVERSIDADE DE COIMBRA

COIMBRA UNIVERSITY PRESS

IMPRENSA NACIONAL 


\section{IX}

\section{Lo pastoril en el teatro de Gil Vicente}

José Javier Rodríguez Rodríguez

Centro de Estudos de Teatro da Universidade de lisboa Universidad del País Vasco 
(Página deixada propositadamente em branco) 
El tipo del pastor acompaña a Gil Vicente a lo largo de toda su carrera teatral. Ahora protagoniza la acción, ahora desempeña un papel secundario, o meramente decorativo. Ya muestra una de sus facetas, ya otra, dentro de la rica gama de caracterizaciones disponibles para la figura en el alto Renacimiento. En las páginas que siguen, trataremos de destacar los aspectos más relevantes de su contribución a la dramaturgia gilvicentina, agrupando los fenómenos en los siguientes apartados: 1) 1502: el comienzo pastoril de un teatro; 2) El pastor y la alegoría; 3) El pastor en el Purgatorio (barca segunda); 4) Pastores de la Sierra de Estrella; 5) El pastor en segundo plano; 6) Pastores y villanos.

\section{1502: EL COMIENZO PASTORIL DE UN TEATRO}

\subsection{VISITAÇÃO}

En la noche del 5 al 6 de junio de 1502 nace en Lisboa el príncipe don João, futuro rey don João III, hijo de la reina doña María y del rey don Manoel I. En la «segunda noite do nacimento do dito senhor», y «estando esta companhia [i. e. la familia real] assi junta [en la cámara de la Reina], entrou um vaqueiro dizendo» las doce coplas que componen el texto de la 
Visitação (también conocida como Auto da Visitação y como Monólogo do Vaqueiro), "a primeira cousa que o autor fez e que em Portugal se representou», según la rúbrica preliminar de la obra en la Copilaçam ${ }^{1}$.

El vaquero irrumpe en la cámara palaciega sin prestar atención a quienes se hallan en ella, absorto en la queja por los «arrepelones» padecidos a manos de los «rascones» (vv. 1-4), víctima de una burla que recuerda la traza del Auto del repelón, atribuido a Juan del Enzina ${ }^{2}$. El cómico enfado deja paso a la admiración ante las "cosas / tan hermosas» que adornan el maravilloso «abrigado» (vv. 13-16). En medio de su estupor, el pastor saluda con torpeza a los circunstantes ("Dios mantenga» — v. 22) y, dirigiéndose a la Reina, explica la causa de su visita: ha sido enviado por el concejo de su aldea para obtener noticias sobre el inminente alumbramiento. Cerciorado de que éste ya se ha producido, expresa su júbilo de modo exultante (haciendo participar en él a los rebaños, los montes y los prados - cf. vv. 56-70), acompañando sus exclamaciones con gestos de entusiasmo que incluyen la ejecución de un salto (cf. vv. 49-51), mientras sus palabras cantan las virtudes de la Reina y del Rey y de sus respectivas casas, que habrán de converger en el recién nacido y fundamentar la grandeza y la dicha de su futuro reinado. Sin embargo, el vaquero evita la prolijidad, dando paso enseguida a la escena muda (quizás amenizada con música) en que, según la rúbrica final de la obra, «entraram certas figuras de pastores e ofereceram ao príncipe os ditos presentes» (i. e., "huevos», "leche», "quesadas», "queso», "miel»; en definitiva, "lo que han podido", dada su condición social —vv. 106-109).

El espectáculo concebido por Gil Vicente forma parte de la tradición de los momos, que conoció un esplendor particular en la corte real portuguesa

1 Cito las obras de Gil Vicente por: Centro de Estudos de Teatro, Teatro de Autores Portugueses do Séc. XVI — base de dados textual on-line (http://www.cet-e-quinhentos.com/) (20/07/2013).

2 El Auto del repelón no figura en el Cancionero de Juan del Enzina hasta la reedición de 1509; su fecha de composición es incierta y su autoría, discutida (cf. Juan del Encina, Obras completas. IV: Teatro, ed. A. M. ${ }^{a}$ Rambaldo, pp. 100-101). Entre el rústico del primer auto vicentino y el gracioso Clarín de La vida es sueño transcurre el largo proceso de adaptaciones que afecta a las figuras de la comicidad en el teatro peninsular moderno; sin embargo, el chistoso plebeyo calderoniano sufre todavía la misma burla al acceder al espacio de los señores, según confiesa al hacer su primera entrada en el segundo acto: "A costa de cuatro palos / que el llegar aquí me cuesta, / de un alabardero rubio...", donde "aquí» designa el espacio palaciego (La vida es sueño, ed. E. Rodríguez Cuadros, vv. 1166-1168). 
del siglo xv (Shergold, 1967, pp. 113-142, especialmente p. 133). En ese marco se explica la brevedad del texto recitado, que da paso al momento principal de la escenificación: la procesión del grupo de figuras ataviadas de modo exótico, con los pintorescos obsequios. Ello permite comprender asimismo la naturalidad con que se confunden la ficción y la realidad, penetrando la primera en el espacio y el tiempo de la segunda, que queda de tal modo incorporada al juego escénico (con la entrada de los pastores fingidos en la que reconocen como cámara verdadera de palacio, donde se comunican verbal y gestualmente con la Reina y sus acompañantes, espectadores y actores al mismo tiempo). Así se comprende también el efecto de sorpresa de la llegada del vaquero, similar al producido por tantos presentadores encargados de anunciar verbalmente el comienzo y fundamento (la invención) del espectáculo de los momos (cf. Surtz, 1979, pp. 67-124).

Shergold (1967, pp. 127-128) señaló la existencia de una clase de momo, a menudo vinculado a la celebración de nacimientos y aniversarios, cuyo número culminante consiste en la entrega de regalos (según ocurre en los dos escritos por Gómez Manrique)³, y apuntó que este tipo de espectáculo podría considerarse como una secularización del drama navideño, donde se adapta a un contexto profano la escena de la adoración de los pastores, pronto adornada con el ofrecimiento de obsequios, a imitación de la adoración de los Magos. En el caso de la Visitação, la cercanía a la representación navideña es evidente, no sólo por la repetición del esquema argumental, sino sobre todo porque los momos aparecen caracterizados como pastores. El fenómeno sugiere un par de reflexiones. Por un lado, la asociación del nacimiento de Cristo al nacimiento del Príncipe (sugerido por el esquema anecdótico y la galería de personajes, pero confirmado por los motivos temáticos y el discurso mismo - cf. Laitenberger, 1991, pp. 66-68) continúa el hábito de hibridación sacro-profana propio del fasto cortesano (cf. Surtz, 1979, pp. 78-79). Por otro, la evocación del drama navideño y la selección de figuras pastoriles para este momo natalicio invitan a pensar que fue concebido

3 De Gómez Manrique. En nombre de las virtudes que iban momos al nascimiento de un sobrino suyo y Un breve tratado que fizo Gómez Manrique al mandamiento de la muy ilustre señora infanta doña Isabel, para unos momos que su excelencia fizo, con los hados siguientes, en Gómez Manrique, Cancionero, ed. F. Vidal González, pp. 657-659 y 668-674. 
bajo la influencia de las novedades escénicas castellanas. En este sentido, el uso del sayagués, el dialecto literario perfeccionado por Juan del Enzina y Lucas Fernández para caracterizar el habla de sus pastores, puede entenderse como un gesto de deferencia hacia la reina María, hija de los Reyes Católicos, pero sirve en cualquier caso como síntoma de que, en su primera producción, Gil Vicente sigue los pasos de los nuevos dramaturgos salmantinos ${ }^{4}$.

\subsection{AUto PASTORIL CASTELHANO}

El calco del patrón característico del drama navideño pastoril no pasó inadvertido a los testigos de la Visitação; al contrario, la rúbrica preliminar de la segunda obra de la Copilaçam, el Auto pastoril castelhano, cuenta: «E por ser cousa nova en Portugal, gustou tanto a rainha velha desta representação [i. e. la Visitação] que pediu ao autor que isto mesmo lhe representasse às matinas do Natal, enderençado ao nacimento do redentor.» No obstante, la propia rúbrica continúa explicando que Gil Vicente no satisfizo exactamente la petición: «E porque a substância era mui desviada, em lugar disto fez a seguinte obra»; esto es, compuso el Auto pastoril castelhano.

La primera parte de la representación muestra la reunión de los pastores. Vemos primero al pastor Gil, dispuesto a pasar la noche de invierno en su majada, y a entretener cantando la espera del sueño. Sus palabras «Yo aquí estoy abrigado / del tempero de fortuna» (vv. 5-6) evocan la convivencia del pastor con las inclemencias del tiempo atmosférico y su íntima satisfacción al sentirse protegido dentro de su refugio; no obstante, dichas palabras insinúan también el espíritu del personaje («um pastor inclinado à vida contemplativa, e anda sempre solitário» — rúbrica preliminar), explicitado enseguida merced a la llegada del pastor Brás, "que o reprende disso» (rúbrica preliminar). La seriedad moral y la sensibilidad religiosa con que Gil entiende el cuidado del rebaño contrastan con el descuido y el escepticismo de Lucas, que viene preguntando por unas cabras perdidas mientras se distraía en un baile, pero que renuncia pronto al esfuerzo de la búsqueda

4 Sobre el sayagués y su empleo por Gil Vicente, véase Teyssier, 1959, pp. 23-75. 
y desprecia el consejo de pedir el auxilio divino para recuperarlas; por el contrario, este mismo Lucas promueve la idea de llamar a otros "zagales» (v. 124) y dar un carácter festivo a la reunión. Acude un nuevo grupo de pastores, encabezado por Silvestre, quien, por su condición de recién casado, da pie a la introducción de los temas burlescos de la genealogía y la dote rústicas. Cansados de charla, los pastores practican sus pintorescos juegos (el abejón, las adivinanzas) hasta que, rendidos por el sueño, se duermen. Comienza entonces la segunda parte de la representación, con la aparición del ángel, que los llama cantando: "Ah pastor / qu'es nacido el redentor» (vv. 255-256). Guiados por Gil, el único que oye la voz del ángel y que se encarga de despertar y persuadir a sus compañeros, los pastores se encaminan cantando hacia el pesebre, donde adoran al recién nacido y le ofrecen sus humildes presentes "com tangeres e bailos» (rúbrica entre los vv. 329 y 330). Después de cantar una "chanzoneta» de despedida, los pastores se alejan conversando sobre lo que han visto, conducidos por el pastor Gil, quien, súbitamente iluminado ("Ahora lo deprendí» - v. 366), celebra el misterio de la Encarnación e ilustra a sus compañeros con paráfrasis y citas del Cantar de los Cantares, la evocación de las profecías veterotestamentarias, e incluso la repetición de alguno de los símiles doctrinales destinados a explicar la conjunción en Cristo de las naturalezas humana y divina. El júbilo de los pastores vuelve a expresarse en el canto con que acompañan su abandono del escenario y el fin de la representación.

Aparte de la coincidencia en una misma ocasionalidad (la celebración de la Navidad en un contexto cortesano) y un mismo esquema argumental (de origen evangélico y litúrgico), el indicio más claro de la imitación de los dramaturgos salmantinos por parte de Gil Vicente es el hecho de que sus pastores hablen sayagués. Resina Rodrigues (1993, pp. 107-115) demuestra con concordancias textuales la proximidad a los autos navideños de Lucas Fernández, si bien el poeta portugués recupera la intervención directa del ángel anunciador, a la manera de la Égloga de las grandes lluvias, de Juan del Enzina 5 .

5 Teyssier (1959, p. 36) demuestra la huella de un drama no navideño de Lucas Fernández, la Comedia de Bras, Gil y Beringuella, de donde parece tomar Gil Vicente los motivos de la genealogía y la dote burlescas. La comedia de Lucas Fernández fue publicada por el autor, 
Según explica también Resina Rodrigues en el lugar citado, la imitación no excluye la originalidad, y la autonomía con que crea nuestro dramaturgo se manifiesta, entre otros aspectos, en tres rasgos evidentes. En primer lugar, en la riqueza lírica y coreográfica: Gil Vicente no sólo repite el expediente de cerrar la escenificación con el canto y baile de los pastores que abandonan la sala, sino que salpica todo el diálogo con danzas y canciones (vv. 23-24: Brás entra a escena cantando; vv. 225-256: el ángel canta el anuncio a los pastores; vv. 284-293: los pastores cantan mientras caminan hacia el pesebre; rúbrica entre los vv. 328-329: los pastores ofrecen sus presentes «com tangeres e bailos»; vv. 330-337: "chançoneta» con que los pastores se despiden de la Virgen María; rúbrica final: "Vão-se cantando»). Además de anticipar una vocación lírica que las producciones posteriores del dramaturgo confirmarán (cf. Calderón, 1996), la riqueza mélica de la pieza navideña vicentina guarda relación a su vez con la segunda originalidad respecto de sus modelos castellanos: la escenificación del momento de la adoración de los pastores, del que aquellos prescinden, y en que se concentra buena parte de las canciones y bailes de los pastores vicentinos. Por último, y sobre todo, la pieza portuguesa adquiere un sabor particular por el protagonismo y el carácter concedidos a uno de los personajes, el pastor Gil (cf. Brotherton, 1975, pp. 17-21).

A pesar de su desconocimiento absoluto de la cultura oficial, que le impide reproducir con corrección la más sencilla de las oraciones de la Iglesia, el rústico Gil muestra una sensibilidad moral y religiosa que le inclina a la soledad contemplativa y que convierte la primera fase del auto en una versión pintoresca y breve del debate sobre la vida retirada, asociado por el Renacimiento a la figura del pastor y ampliamente

junto con el resto de su obra conocida, en el volumen titulado Farsas y églogas al modo y estilo pastoril y castellano (Salamanca, 1514), aunque la fecha de composición y representación de las piezas en él contenidas debe de ser anterior en varios años a la de edición. La Égloga de las grandes lluvias fue compuesta por Juan del Enzina para la Nochebuena de 1498, si bien no se incorporó a su Cancionero hasta la reedición de 1507. En cuanto al ángel que anuncia el Nacimiento a los pastores, debe recordarse que Lucas Fernández evita la comparecencia de esa figura y encomienda su tarea a un pastor que ha recibido previamente el aviso sobrenatural. A juicio de Brotherton (1975, pp. 8-17), Lucas Fernández oculta al ángel para suavizar las connotaciones de irreverencia que podría adquirir la actitud peculiarmente burlesca y refractaria de sus pastores ante la noticia de la Encarnación, que convierte ese segmento en el verdadero núcleo del drama. 
desarrollado, por ejemplo, en las églogas morales de Sá de Miranda 6 . De tal manera, el espectador cobra conciencia desde el principio del tema verdadero de la obra, mientras que en las escenas iniciales de los modelos salmantinos solo unas pocas alusiones veladas recuerdan que el juego escénico tiene un propósito que transciende la exhibición regocijante de unas figuras exóticas y ridículas. Su peculiar disposición de espíritu explica asimismo que sea Gil el único pastor que despierta a las palabras del ángel, y que se encarga de transmitirlas a sus compañeros. A partir de ese instante el rudo Gil comienza a beneficiarse de una iluminación que se hace perfecta en presencia del Recién Nacido y su Madre, y que le permite actuar como ilustrador de los demás pastores en la escena que sigue a la adoración, cuando manifiesta su júbilo y dibuja los contornos del misterio mediante la paráfrasis de los textos bíblicos y litúrgicos.

\subsection{AUTO DOS REIS MAGOS}

Explica la rúbrica previa al Auto dos Reis Magos que «a dita senhora rainha, muito satisfeita desta pobre cousa [i. e. el Auto pastoril castelhano], pediu ao autor que pera dia dos Reis logo seguinte lhe fizesse outra obra. E fez a seguinte». Entra primero Gregorio, un pastor que se ha perdido en su camino hacia el portal de Belén, hacia donde partió trece días antes, abandonando sus rebaños, para obedecer el exhorto del ángel. Pregunta a otro pastor, de nombre Valerio, que le conduce hasta fray Alberto, un ermitaño, que se confiesa "religioso / perezoso» (vv. 99-100) ante la muestra de piedad, cándida pero vívida, de Gregorio. Valerio, por el contrario, tiene un talante burlón, y (como lo hacen los pastores de Lucas Fernández en la Égloga o farsa del Nascimiento) somete a un interrogatorio malicioso al ermitaño, con visos satíricos ("Buldas debéis de traer / a vender / que os estáis chacorveando» - vv. 123-125), pero de alcance principalmente

6 Sobre la tradición temática y su asociación a la literatura pastoril, cf. Busnardo-Neto, 1974, pp. 34-41. 
burlesco («Decidnos padre bendito / halláis scrito / si es pecado estrañudar?» - vv. 130-132), que culmina en el elogio naturalista del amor sexual, vedado por el sexto mandamiento (cf. Resina Rodrigues, 1993, pp. 109-111). Llega entonces un caballero preguntando por el camino de Belén. El díscolo Valerio no puede reprimir una burla, que excita la indignación del señor (insinuándose un enfrentamiento que recuerda diversas escenas de las primeras églogas profanas salmantinas: la Égloga en recuesta de unos amores, de Juan del Enzina; la Farsa o cuasi comedia de una doncella y un pastor y un caballero y la Farsa o cuasi comedia de dos pastores e un soldado e una pastora, de Lucas Fernández $)^{7}$. La noticia de que el caballero extraviado viene acompañando a tres reyes que peregrinan siguiendo una estrella para adorar al Mesías recién nacido orienta el drama hacia su culminación: en primer lugar, Fray Alberto parafrasea jubiloso las profecías de la Epifanía; a continuación, el pastor descortés se arrepiente de sus ofensas y obtiene el perdón del caballero. El diálogo puede concluir y dejar paso al espectáculo final: los Magos entran cantando y, mientras la canción es repetida por el conjunto de los actores, ofrecen sus presentes de oro, incienso y mirra.

Con todo, es posible que este remate, que apenas disimula su carácter abrupto bajo la forma del momo, haya venido condicionado por la premura con que el dramaturgo hubo de componer la pieza, según sugiere la rúbrica final: "E acaba em breve, porque nãm houve espaço pera mais.» En el corto lapso de trece días, sin embargo, Gil Vicente supo hallar recursos para asegurar el efecto dramático de su obra, animando el propósito de celebración religiosa mediante la explotación del contraste de caracteres en la pareja formada por el pastor devoto y el pastor burlón, así como la incorporación de motivos satírico-burlescos a cargo de este último (en la encuesta del ermitaño y en el desacato al caballero), expresión de la confusión ideológica y moral que el pastor mundano termina por superar gracias a la experiencia de la Epifanía (cf. Brotherton, 1975, p. 21).

7 La Égloga en recuesta de unos amores forma parte del Cancionero de Juan del Enzina desde su primera edición, en 1496. 


\section{El PASTOR y LA ALEgoría}

\subsection{AUTO DA FAMA}

Estrenado en 1510 ante la reina doña Leonor, y repuesto con algunas modificaciones de detalle ante el rey don Manuel en fecha no anterior a 1513 (cf. Serôdio, "Apresentação"), el Auto da Fama desarrolla un argumento sencillo. Una pastorcilla, que guarda sus patas acompañada por un parvo, rechaza sucesivamente los requerimientos amorosos de tres caballeros, que pretenden llevársela a sus tierras. Como se ve, Gil Vicente se sirve del esquema anecdótico de la pastorela trovadoresca, que había sido llevado al teatro por Juan del Enzina en su ya mencionada Égloga en recuesta de unos amores (cf. Gerhardt, 1975, pp. 31-43 y 130-140). Ocurre, sin embargo, que el nombre de la mocita es Portuguesa Fama y que los caballeros, un francés, un italiano y un castellano, son personificaciones de sus respectivos estados. En efecto, la pastorela presenta en este caso un explícito valor alegórico, con la intención de demostrar que «a fama é ũa tam gloriosa excelência que muito se deve de desejar, a qual este reino de Portugal está de posse da maior de todolos outros reinos» (rúbrica preliminar).

El dramaturgo se sirve de expedientes como la estupidez y pereza del parvo, la sencillez pastoril de la protagonista, o el plurilingüismo (en especial, los remedos de los idiomas francés e italiano), para proporcionar a la obra efectos pintorescos y cómicos, sin por ello olvidar el propósito principal, vehiculado por la alegoría, que culmina en la escena final con la coronación y la entronización de la Fama Portuguesa en un carro triunfal por parte de las que se presentan como las dos grandes virtudes lusitanas, Fe y Fortaleza. Si la mencionada égloga de Juan del Enzina pudo inspirar a Gil Vicente la idea de dramatizar la pastorela, la posibilidad de aprovecharla como plano anecdótico de una metáfora continuada de significado político puede haberle sido sugerida por la tendencia general hacia el simbolismo del fasto cortesano, pero invita a pensar en la influencia de las variedades alegóricas y polémicas de la pastoril romance y neolatina (cf. 
Gerhardt, 1975, pp. 56-64), que ayudan a comprender también una pieza como la Égloga de Francisco de Madrid, representada ante la corte castellana en 1495 y que aborda bajo el velo bucólico la invasión de Italia por parte Carlos VIII de Francia (cf. Surtz, 1979, pp. 98-100).

\subsection{AUTO DA FÉ}

La rúbrica preliminar informa sobre las circunstancias de la escenificación: "A seguinte representação foi representada em Almeirim ao mui poderoso rei don Manoel [...] nas matinas do Natal [...] na capela.» Los vv. 228-229, por su parte, indican el año: 1510. Estando, pues, la "corte real» (v. 298) reunida en la capilla de palacio con motivo de los oficios litúrgicos navideños, entran en ella dos "pastores simpres» (acotación preliminar), en busca de una fiesta de naturaleza imprecisa. Impresionados por la solemnidad de la celebración y su aparato, manifiestan su ignorancia mediante varias conjeturas desatinadas sobre los principales elementos del adorno del templo. Precisamente cuando expresan su deseo de hallar algún letrado que pueda sacarles de su incomprensión, entra una figura elegantemente vestida, que se arrodilla, pone las manos, y ora en voz baja, mientras los pastores, comprendiendo la inconveniencia de sus actitudes previas, imitan torpemente los decorosos ademanes de la dama. Concluida su oración, la misteriosa figura se pone en pie y atiende (en portugués) las preguntas de los pastores (en sayagués): revela su identidad y define el concepto que personifica, la fe; explica el significado de los adornos cultuales que a los pastores les resultaban enigmáticos; declara el sentido de la celebración, esto es la rememoración del misterio de la Encarnación del Verbo. Aunque los simples pastores, de habla sayaguesa, entienden el idioma portugués de Fe, no alcanzan a comprender sus explicaciones, porque el sistema conceptual e imaginístico de su argumentación (propio de la teología y la literatura religiosa) les es completamente ajeno; con todo, reconocen por fin la naturaleza de la "boda» (v. 1) que se está celebrando, plantean nuevas preguntas sobre su significado e, incitados por $\mathrm{Fe}$, se suman a la fiesta con un canto popular, seguido por una «enselada 
que veio de França» (acotación final) cantada a cuatro voces por otros tantos pastores que acuden oportunamente para acompañar de tal modo la salida de los actores y el fin de la representación.

Como destaca Gouveia ("Apresentação»), la «invenção" (acotación preliminar) vicentina se fundamenta en la fusión de los tiempos y espacios de la representación y de lo representado, valiéndose de una convención esencial en la Visitação y que el primer teatro renacentista hereda de la tradición de los momos (Surtz, 1979, pp. 76-78 y 88-95). Ahora bien, si la ficción del Auto pastoril castelhano y del Auto dos Reis Magos confundía en uno el tiempo contemporáneo y el evangélico, según un hábito practicado también en las piezas navideñas de Juan del Enzina y Lucas Fernández (el pastor Gil que alude al rey don João II es el mismo que recibe el anuncio del ángel en las inmediaciones de Belén; el pastor Gregorio, que busca al Mesías recién nacido tras oír el mensaje angélico, habla con un fraile cristiano al que pide que diga "un trintanario / al rosario", vv. 84-85), el Auto da Fé establece una diferencia explícita. Así, los pastores preguntan: «Qué años ha que aqueció [el nacimiento del Mesías]?», y Fe responde: «Mil e quinhentos e dez.» (vv. 228-229). Por esta vez, el drama se detiene ante el umbral del rito, sin penetrar en su dominio, quizá porque la fe, concepto personificado como figura central de la representación, cobra sentido precisamente en esa distancia entre la noche relatada en el Evangelio y la noche de 1510 en que se rememora aquélla, puesto que «fé é crer o que nam vemos» (v. 129); al mismo tiempo, la distancia temporal así establecida permite explicitar la actitud presupuesta en el auditorio de toda escenificación navideña: "Tanto monta se agora / contemplares aquela hora / como s'agora passara» (vv. 233-235).

Por otro lado, Gil Vicente prescinde en esta ocasión del argumento evangélico, reteniendo dos elementos. En primer lugar, los pastores simples, de habla sayaguesa, con su virtualidad pintoresca y cómica. Además, el personaje del mensajero e ilustrador, sucesor de los ángeles, ermitaños $\mathrm{y}$ pastores previamente informados que transmiten el anuncio y revelan el sentido del Nacimiento a los pastores ignorantes en las obras navideñas anteriores del autor, así como en sus modelos salmantinos. En este caso, el dramaturgo asigna ese papel a una personificación conceptual, Fe, 
introduciendo el procedimiento alegórico en el teatro navideño, como lo había hecho recientemente en la escenificación política (Auto da Fama) y, si no hay errata en la fecha de 1508 que indica la Copilaçam, también en el drama penitencial (Auto da alma).

El diálogo de la sabia maestra alegórica y los torpes discípulos pintorescos yuxtapone, para deleite del público, claras definiciones teológicas y divertidos disparates pastoriles; no obstante, el efecto característico de la obra procede del contraste mismo de ambos discursos, inasequibles el uno para el otro. Gil Vicente se complace en amplificar el tema de la incomprensión de las explicaciones de Fe por parte de los rústicos, poniendo de relieve y explotando con intención cómica la distancia entre la alta cultura (eclesiástica y cortesana) y la cultura popular. Así, la encendida poesía hímnica y litúrgica con que Fe evoca el misterio de Nochebuena obtiene la siguiente réplica por parte de Brás: «Que ño os entiendo ño [...] Si es noche de Navidá / esa es otra sebandija...» (vv. 204-209).

Ahora bien, la insuficiencia intelectual de los pastores no suscita la censura, ni empaña el regocijo. El texto suministra varios indicios en este sentido. En primer lugar, se insinúa que toda carencia doctrinal puede suplirse mediante la aceptación del credo a pies juntillas (vv. 212-227). En segundo lugar, se subraya el elogio de la pobreza y de la humildad implícito en las circunstancias del Nacimiento, simbolizadas desde siempre por los pastores (vv. 264-295). En tercer lugar, la propia figura de Fe pone fin a sus enseñanzas invitando a los rústicos a festejar el misterio a su modo, con sus canciones tradicionales (vv. 300-303). Por último, Brás cierra el diálogo con una réplica que lesiona la verosimilitud, pero confirma el decoro, asegurando al espectador que el proceso de conversión de los pastores (eje temático del drama navideño, según la sugestiva interpretación de Brotherton, 1975, pp. 1-45) se ha cumplido.

\subsection{AUTO DA SEBILA CASSANDRA}

La rúbrica preliminar informa de que el Auto da sebila Cassandra fue representando ante la reina doña Leonor en el monasterio de Enxobregas 
en los maitines de Navidad. No indica el año, que puede corresponder a cualquiera del lapso 1510-1515, si bien Révah (1959) aduce argumentos convincentes en favor de 1513.

Una actriz «em figura de pastora» recita dos coplas donde expresa su resuelta decisión de mantenerse soltera. En consecuencia, rechaza al «zagal polido» que la aborda confiado en sus cualidades personales y en la aquiescencia de las tías de la pretendida. Ésta, de nombre Casandra, desprecia las razones del mozo, Salomón, y apoya su actitud enumerando los males del matrimonio desde el punto de vista femenino. Mientras ella interpreta la canción de estribillo "Dicen que me case yo / no quiero marido no" (vv. 198-217), el perplejo pretendiente va en busca de las tías de la doncella, Erutea, Peresica y Ciméria, que entran «com o pastor Salamão em chacota» (rúbrica entre los vv. 217 y 218) e intentan convencerla, aunque en vano, aduciendo los bienes de naturaleza y fortuna del joven. Como último recurso, el desdeñado recurre a sus propios tíos, Abraham, Moises e Isaías. Llegan "cantando todos quatro de folia» una cantiga cuyo tema dice "Sañosa está la niña / ay Dios quién le hablaría?» (rúbrica entre los vv. 310-311 y vv. 311-319) y procuran, sin éxito, ablandar a la moza con regalos. Ni el joven ni los parientes han logrado persuadir a la esquiva doncella, que confirma una y otra vez su opinión negativa sobre el matrimonio, incluso cuando uno de los ancianos recuerda su carácter sacramental. Finalmente, Casandra desvela el verdadero motivo por el que desea permanecer soltera: presiente que Dios ha de encarnar en una virgen y está convencida de que ella misma será la elegida. La primera parte del vaticinio es confirmado por las otras tres sibilas, sus tías, que declaran su propia presciencia sobre el misterio de la Encarnación. Su segunda parte, sin embargo, es desmentida como desatino por Isaías, Abraham, Moises y Salomón, que contraponen la soberbia de Casandra y la humildad que las profecías veterotestamentarias destacan como cualidad esencial de la virgen escogida por el Señor. El tono exultante de todas estas evocaciones se quiebra cuando Erutea expone la previsión sobre el fin del mundo. Sin embargo, la inquietud dura sólo tres coplas, porque a continuación «abrem-se as cortinas onde está todo o aparato do nacimento» (rúbrica entre los vv. 652 y 653), mientras los ángeles cantan una nana a lo divino que sirve de anuncio 
y llamada a los pastores-profetas y pastoras-sibilas, quienes se dirigen al portal "cantando em chacota» (rúbrica entre los vv. 686 y 687). Uno por uno, los profetas adoran al Niño y las sibilas a la Virgen, facilitando Casandra la transición, al reconocer primero su error ante el Hijo y al encomendarse después a la Madre. Para expresar su alegría, los adorantes cantan y bailan "de terreiro de três por três» la cantiga "feita e ensoada polo autor» cuyo estribillo reza "Muy graciosa es la doncella / cómo es bella y hermosa" (vv. 767-779), dedicada a María, y se despiden con el villancico de tema "A la guerra / caballeros esforzados / pues los ángeles sagrados / a socorro son en tierra / a la guerra» (vv. 780-793).

El resumen pone en primer plano la abundancia y diversidad de materiales usados en la representación. Por el contrario, la lectura de la obra sorprende por la naturalidad con que lo heterogéneo se reduce a coherencia, asegurando la eficacia dramática y escénica. En este sentido, Révah (1959) distingue dos principios estructurales. En primer lugar, una construcción plástica y musical, que rige las entradas y salidas y explica el diseño simétrico de varias escenas (pp. 168-169). En segundo lugar, una construcción teatral (o, quizá mejor, dramática, o argumental), que divide la pieza en secuencias diferenciadas pero complementarias: la comedia rústica de la serrana refractaria al matrimonio, la adoración del Mesías recién nacido y su madre, unidas ambas por el segmento central de diálogo que evoca las profecías de la Redención, a partir del momento en que la pastora Casandra, apelando a su condición de sibila, revela su vaticinio de la Encarnación y desvela el error de considerarse la virgen escogida (pp. 169172). Révah suscribe las conclusiones de Gerhardt (1975, pp. 141-146) sobre la sutileza con que el dramaturgo liga de modo orgánico la introducción (a primera vista, puramente profana) y la culminación devota de la obra, sembrando en aquélla discretas alusiones que, sin entorpecer el tono cómico, preparan la evolución hacia lo sagrado. Se trata, como escribe Lida (1966, p. 158), de «un juego mutuo en que lo sagrado se enriquece por la plasticidad y gracia de lo rústico, y lo rústico se ennoblece y ahonda por el simbolismo trascendente de sus asociaciones sagradas".

Lida y Révah, en los ensayos citados, esclarecen las fuentes litúrgicas, literarias e iconográficas de donde procede el elenco de personajes y su 
«Simbolismo trascendente». Por lo que hace a la condición pastoril asumida aquí por sibilas y profetas, ambos la consideran herencia del modelo de auto navideño propuesto por Juan del Enzina; de manera más precisa, Révah hace suyas las ideas de Wardropper (1953) y considera que Gil Vicente se inspira en la égloga segunda del salmantino, que había abierto el camino a la alegorización del pastor del Nacimiento al indicar de modo explícito que los cuatro rústicos, llamados Juan, Marcos, Mateo y Lucas, representaban a los cuatro evangelistas (p. 170). Ahora bien, el gesto por el cual el dramaturgo preserva o confiere la condición pastoril a sus sibilas y profetas resulta esencial, de modo que quizá valga la pena considerarlo un tercer principio estructural, con la función de engranar los dos mencionados arriba y hacer posible tanto la riqueza como la coherencia de la obra.

En efecto, el hecho de que sibilas y profetas actúen en figura de pastoras y pastores permite sobreponer en una sola representación el recuerdo de las varias tradiciones escénicas navideñas: sobre el esquema derivado del officium pastorum, según el cual se suceden la escena costumbrista de los pastores antes del Nacimiento, el anuncio de los ángeles que les hace ponerse en camino y la adoración, estos peculiares pastores reproducen las paráfrasis veterotestamentarias del ordo prophetarum y los vaticinios del Canto de la Sibila. Al mismo tiempo, la faceta pastoril de los personajes ofrece los recursos para evitar el peligro de excesiva solemnidad derivado de tal espesor simbólico: la caracterización rústica se conjuga a deseo con el abolengo sacro para insinuar la significación religiosa sin incurrir en hieratismo; el tema de la sibila engañada se introduce como el caso de la serrana desdeñosa, elevando el prólogo costumbrista tradicional en el drama pastoril navideño a la condición de deliciosa comedia de amores rústicos; la afición de los pastores por el canto y la danza autoriza el enriquecimiento de la acción y el diálogo con frecuentes números líricos, musicales y coreográficos, que pautan el ritmo escénico. Es, en definitiva, la caracterización pastoril de los personajes el instrumento de que se vale genialmente el dramaturgo para reducir a unidad la variedad de los materiales empleados, disponer su densidad simbólica en un movimiento de insuperable gracia y envolver la orientación devota y el mensaje moral en la atmósfera regocijada propia de la festividad navideña. 


\subsection{AUTO DOS QUATRO TEMPOS}

La rúbrica preliminar reza: "Esta seguinte obra se chama dos Quatro Tempos. Foi representada ao mui nobre e próspero rei dom Manoel na cidade de Lisboa, nos paços d'Alcáceva na capela de sam Miguel, por mandado da sobredita senhora sua irmã [D. Leonor] nas matinas do Natal.» En consecuencia, debe de haberse compuesto antes de 1521, año del deceso del rey D. Manoel, y es probable que lo haya sido entre 1511 y 1515 (cf. Révah, 1959, p. 177).

El auto comienza con la entrada de un grupo celeste: un serafín proclama, ante un arcángel y dos ángeles, el nacimiento del Mesías, que supone el cumplimiento de la promesa de redención y la renovación radical de la historia del mundo. Los cuatro caminan hasta el pesebre, donde expresan su adoración cantando un villancico que adapta el Te Deum. Concluida esta escena, comienza la de las cuatro estaciones, que entran de una en una. En primer lugar, "um pastor que significa o Inverno» (rúbrica entre los vv. 108 y 109), que anima su monólogo en sayagués con la glosa intercalada de una cantiga (cuyo estribillo reza: "Mal haya quien los envuelve / los mis amores / mal haya quien los envuelve» — vv. 109-111): el pastor se queja de las inclemencias naturales propias de la estación, poco propicia al amor. Apenas se ha quedado dormida esta figura, entra la de la Primavera ("Verão» - didascalia del v. 181), que mezcla también la glosa de una canción en su monólogo (de tema: "En la huerta nasce la rosa / quiérome ir allá / por mirar al ruiseñor / cómo cantaba» - vv. 181-184), donde expresa el gozo de la vitalidad resurgida. Enmudece ante la llegada de Estío («ũa figura muito longa e muito enferma, muito magra com ũa capela de palha» — rúbrica entre los vv. 253 y 254), abrumado por la sed, la sequedad y las fiebres, que no deja de defenderse, sin embargo, del desprecio de la Primavera, recordándole la vanidad de su verdor. La comparecencia del Otoño, la estación de los frutos, completa la representación del ciclo temporal del año.

Irrumpe entonces la figura de Júpiter, que proclama la sumisión del cosmos y los dioses paganos al Dios encarnado. Compele a los cuatro tiempos a encaminarse al pesebre, y los conduce hasta allí, al son de una «cantiga

francesa" que comienza "Ay de le noble / villa de Pariz" (vv. 448-449 y 
rúbrica precedente), donde la divinidad grecolatina y sus acompañantes expresan sucesivamente su adoración. Acabada ésta, "entra David en figura de pastor» (rúbrica entre los vv. 577 y 578) para cantar las alabanzas del Señor y postrarse a su vez como adorante ante el pesebre. Por último, ángeles, estaciones, Júpiter y David se unen en el canto del Te Deum, con que termina la representación.

Asensio (1949) explicó la orientación y contextura de esta obra sorprendente. En su búsqueda de innovación para el drama navideño, Gil Vicente se aparta del tono pintoresco y popular de las piezas pastoriles y opta por las notas solemnes, de origen pregótico, predominantes en los himnos de los oficios. De hecho, la inspiración vicentina procede básicamente del "Oficio de Nuestra Señora que se reza en adviento» y se le puede considerar "un comento dramatizado del Laudate y el Benedicite» (p. 80), cuyas palabras cobran cuerpo escénico con el auxilio de la tradición iconográfica y se amplifican con la erudición de Bartholomaeus Anglicus y Juan de Mena.

El componente pastoril se difumina: "escasos rastros» de sayagués, "un rápido cambio de injurias entre Estío y Verano», la ligera alusión de Invierno a sus amores con la hija del herrero son todas las huellas señaladas por Asensio (p. 82). No obstante, la contribución de la tradición pastoril es mayor de lo que parece. En primer lugar, la estructura de la obra no deja de estar en deuda con la propia de piezas como el Auto pastoril castelhano: así, una vez nacido el Mesías (como se muestra en la primera secuencia del drama, con el diálogo de los ángeles y la exhibición del pesebre), el segmento de las estaciones en esta obra ocupa la posición del diálogo costumbrista de los pastores en aquéllas; el mensaje de Júpiter aquí cumple la función del emitido por el ángel anunciador allí; y la adoración que sigue se corresponde con la secuencia final del modelo del drama navideño pastoril. Precisamente el recuerdo de la tradicional adoración de los pastores añade coherencia a la comparecencia final de David, explícitamente caracterizado como pastor (un pastor-rey y pastor-profeta con la misma ambivalencia de los patriarcas del Auto da sebila Cassandra), que apela a la asociación tradicional del pastor con el canto para legitimar ficticiamente el tono lírico del salmista en las alabanzas previas a la adoración (vv. 579-589). 
En cualquier caso, el dramaturgo parece haber vacilado en el uso de la materia pastoril en esta obra, como da a entender la imprecisa caracterización de las estaciones. Solamente el Invierno aparece definido explícitamente como pastor, en plena coherencia con los temas y la forma de sus palabras. El personaje de la Primavera entra expresándose en sayagués, pero los rasgos del dialecto rústico se difuminan después en su discurso, así como en el de Estío y Otoño. En contraste con ello, los personajes de los cuatro tiempos se afirman como símbolos poderosos del sentimiento de la naturaleza, precedentes de la culminación poética del tema en la Tragicomedia de Inverno e Verão (cf. Gerhardt, 1975, pp. 146-152).

\section{El pastor en el PURGatório (bARCA SEGUNDA)}

La obra que vamos a comentar ahora "foi representada à muito devota e católica rainha dona Lianor no Hospital de Todolos Santos na cidade de Lisboa, nas matinas do Natal. Era do Senhor de 1518 anos» (rúbrica preliminar). El lugar escogido por la reina para la escenificación sugiere que la concibió como un gesto de caridad cristiana que extendería mas allá de los muros de los palacios cortesanos el efecto reconfortante atribuido a su modelo, la Barca do Inferno, interpretada el año precedente "pera consolação da muito católica e santa rainha dona Maria, estando enferma do mal de que faleceu» (rúbrica preliminar). La confluencia de esta intención moral y piadosa, del lugar y el auditorio seleccionados y de la circunstancia navideña explican los rasgos específicos de la obra.

La representación comienza con la llegada del ángel y el demonio, patrones de las dos embarcaciones colocadas en los extremos opuestos del escenario, destinadas a transportar al cielo o al infierno a las almas que han merecido en su vida la salvación o la condenación. En realidad, no es un ángel el que llega, sino tres, para completar el trío de voces necesario para cantar el romance de obertura. El arráez infernal, por su parte, cuenta con la ayuda de un compañero. Unos y otros ofrecen las informaciones precisas para que el auditorio se haga cargo de la situación imaginaria y su significado, insistiendo en la circunstancia particular de 
que «naceu hoje Cristo» (v. 72). El ángel anima a subir en la nave de la Iglesia, la nave de la salvación, aprovechando el caudal de gracia que mana de la Encarnación: "Quem quer ir ò paraíso? / À glória à glória senhores / oh que noite pera isso / quam prestes quam improviso / sois celestes moradores» (vv. 46-50). El demonio se sorprende de hallar su puerto vacío y su embarcación en seco, hasta que el compañero le explica: «este serão / é pera nós grande praga / e trabalhamos en vão / porque a promessa d'Abraão / hoje é a paga» (vv. 118-122).

Uno por uno, comparecen después en la fatal orilla el labrador, la regateira labradora, el pastor, la moza pastora, el niño de pocos años y el tahúr. En la altercación con los patronos de las dos naves se hace el examen moral de sus vidas y, en los cuatro primeros casos, se dictamina que deben esperar por un tiempo indefinido en la playa, purgando sus pecados, antes de poder embarcarse hacia la gloria; las dos últimas figuras siguen otro destino, puesto que la criatura inocente es admitida de inmediato en la nave de la salvación, mientras que el jugador es condenado sin demora a tomar la embarcación del Infierno. El espectáculo acaba con este efecto de contraste traspuesto al plano musical: «Saem-se os Diabos do batel e com ũa cantiga muito desacordada levam o Taful. E os anjos cantando levam o Menino.» (rúbrica final).

Como se ve, Purgatório (barca segunda) retoma la invención creada para la Barca do Inferno y la adapta a la circunstancia navideña. Ello explica, en primer lugar, la galería de personajes: puesto que «esta noite é dos pastores» (v. 488), son ellos los que deben remplazar a los tipos sociales propios de la sátira que pueblan la primera barca (cf. Grande Quejigo, 2004, p. 42). Ahora bien, dado que la convención establecida en la Barca do Inferno pedía que cada personaje representara un estado social, el dramaturgo no podía multiplicar los pastores, sino que hubo de añadir otras figuras que nutrieran el desfile de las almas. Para ello, recurrió a tres expedientes: el primero, diferenciar el sexo masculino y femenino dentro de cada estado; el segundo, añadir al pastor y la pastora los personajes del labrador y la labradora; por último, culminar la procesión de las almas destinadas al purgatorio con el contraste del niño y el tahúr, destinados al cielo y al infierno, respectivamente. 
En cierto modo, la convivencia de labradores y pastores constituye un síntoma de la hibridación fundamental que caracteriza la pieza: el labrador procede de la tradición de las danzas de la muerte, uno de los modelos básicos en la concepción moral y satírica de las barcas (Asensio, 1953, pp. 65-68); el pastor recuerda al espectador el contexto navideño donde esa concepción viene ahora a injertarse. Así, la relación entre uno y otro presenta dos aspectos diferentes. Por un lado, la adición del labrador y la labradora al pastor y la pastora no parece quebrar el decoro del teatro navideño, en cuanto que unos y otros comparten la pertenencia al mismo mundo campesino; a todos ellos parece referirse la rúbrica inicial cuando explica: «trata-se per lavradores». Por otro lado, sin embargo, el tratamiento de las dos parejas no es idéntico.

El labrador, con su arado a cuestas, compone un símbolo ambiguo: representa la dureza de la existencia de «los que viven por sus manos», según la célebre expresión de Jorge Manrique, existencia consagrada al trabajo físico e indefensa ante al abuso de los poderosos; al mismo tiempo, encarna el sentimiento poco piadoso de que una vida de penalidades, unida al cumplimiento formal de los ritos y mandamientos eclesiásticos, asegura por sí sola la salvación. De modo semejante, la labradora lleva encima su «canistrel», donde porta los "pecados» (vv. 370-372); y es que, por más que se defienda recordando la necesidad de sobrevivir en un mundo corrompido, ella sola es la responsable de sus malas prácticas de regateira. En ambos casos, Gil Vicente opta por un retrato realista, adecuado a la elaboración de un mensaje satírico-moral, según la tradición de las danzas de la muerte, incorporada a su concepción de las Barcas.

El pastor y la pastora, por el contrario, escapan a ese enfoque. El pastor, que se expresa en un dialecto rústico más caracterizado y cómico, no ha visto nunca un barco («Isto é cancelo ou picota / ou sonefica algorrém / não lhe marra ela aqui gota / de ser isto terramota / pera enforcar alguém» — vv. 435-439), ni reconoce al demonio ("Sois buzaranha» — v. 466) ni al ángel ("Este é milhor artesão» — v. 519). En definitiva, se hace acreedor al apodo de «rústico perdido» que le dirige el arráez infernal (v. 477), quien no oculta su sorpresa ("Quem te pôs no coração / falares cousa tam boa / que tu nam tens descrição?» — vv. 513-515) cuando el pastor bobo, bene- 
ficiándose de la predilección divina por los pobres de espíritu (cf. Brotherton, 1975, p. 64), manifiesta tener conciencia del misterio navideño y su significado de redención, al replicarle: «Esta noite é dos pastores / e tu decho estás em seco / e salvam-se os pecadores [...] porque em festa de tal glória / nam hás ninguém de levar [...] Nam podes nada fazer / na noite que quis nacer / Cristo filho de Davi» - vv. 488-512). Al contrario del labrador (que «levava o Credão at'ò cabo» - v. 232), el pastor revela su completo desinterés por las más elementales oraciones de la Iglesia y su confianza en el buen sentido moral y en una vivencia irreflexiva de la fe: "Assaz avonda ao pastor / crer en Deos e não furtar / e fazer bem seu lavor / e dar graças ao senhor / e fogir de não pecar. // E crer na igreja assi junta / com paredes e telhados / alicéceres e furados / e nam curar de pregunta / e dar ò demo os pecados. / Eu nunca matei nem furtei / nega uvas algũa hora / nem nunca xemeriquei / nem xeremicos falei / como lá se usa agora” vv. 544-557). Incluso la última acusación del diablo, que denuncia su agresivo comportamiento sexual, apunta al rasgo esencial del personaje, que no es otro que su primitivismo, su cercanía a la naturaleza.

La pastora, por su parte, es una "menina" simple, que rehuye al demonio impulsada por el miedo y que muestra la misma incultura teológica del pastor. Para ella, no hay diferencia entre Dios y la sagrada forma (redonda y blanca) de la eucaristía, vista con frecuencia, porque la pastora disfrutaba de los oficios divinos sin comprenderlos, representando así otra modalidad de la vida religiosa popular. Tanto en su caso como en el de su pareja masculina, la sentencia de purgatorio parece demasiado severa. El lector se pregunta si personajes como estos están sujetos a cualquier clase de responsabilidad. Porque, matizando la caracterización de labradores y pastores, Gil Vicente ha ensayado una distinción que se afianzará en su producción posterior. Ambos tipos conservarán la virtualidad cómica asociada a la figura rústica, pero el dramaturgo preferirá recurrir al labrador cuando le interese el retrato realista de un tipo social, con propósito moral o satírico, mientras que se valdrá de los pastores como figuras literarias, asociadas a la evocación de un mundo arcaico y presocial, con sus sentimientos elementales y sus coloristas expresiones musicales y poéticas. 


\section{Pastores de la Sierra da Estrella}

\subsection{AUTO PASTORIL PORTUGUÊS}

La rúbrica preliminar presenta esta obra como sigue: «Auto em pastoril português, representado ao muito alto e poderoso rei nosso senhor dom João, o terceiro em Portugal deste nome, na sua cidade d'Évora, per Natal. Era do Senhor de 1523.»

La escenificación tiene dos partes. En la primera, asistimos a los diálogos amorosos de tres parejas de pastores y pastoras eslabonados en una cadena de amores discordantes: Joane quiere a Caterina, que ama a Fernando, que desea a Madanela, que pretende a Afonso, que corteja a Inês, que tiene puesto su afecto en Joane. El tema, bautizado en los vv. 348-349 («Isto chamam amor louco / eu por ti e tu por outro"), no es desarrollado en el tono de patetismo sentimental a que lo elevará Montemayor en su Diana ${ }^{8}$, sino en un registro cómico, sostenido sobre dos recursos complementarios: por una parte, la degradación paródica de las ideas y actitudes tópicas del enamorado en la literatura cortesana; por otra, la substitución del refinamiento expresivo de dicha literatura por un estilo rústico, que no es ya el sayagués de Juan del Enzina y Lucas Fernández, sino un dialecto literario portugués equivalente (cf. Teyssier, 1959, pp. 76-181), que el dramaturgo había venido elaborando en obras como Purgatório (barca segunda), y que en esta pieza alcanza su perfección (al tiempo que su efecto humorístico más pronunciado, precisamente por aplicarse a la materia amorosa ante un público cortesano acostumbrado a verbalizarla con muy otra retórica).

8 Compárese con el siguiente fragmento del relato de Selvagia, en el libro primero: "Ved qué extraño embuste de amor: si por ventura Ysmenia iba al campo, Alanio tras ella; si Montano iba al ganado, Ysmenia tras él; si yo andaba en el monte con mis ovejas, Montano tras mí; y si yo sabía que Alanio estaba en un bosque donde solía repastar, allá me iba tras él. Era la más nueva cosa del mundo oír cómo decía Alanio sospirando "iAy, Ysmenia!», y cómo Ysmenia decía "¡Ay, Montano!», y cómo Montano decía "iAy, Selvagia», y como la triste de Selvagia decía «iAy, mi Alanio!» (Jorge de Montemayor, La Diana, ed. A. Rallo, pp. 149-150). 
La segunda parte arranca con la entrada de Margaída, una nueva "pastora que achou ũa imagem de nossa senhora e trá-la escondida num feixe de lenha» (rúbrica entre los vv. 401 y 402). Margaída no explica su hallazgo inmediatamente, sino que gana tiempo para serenar sus emociones y concita el interés de sus oyentes proponiéndolo como tema de una adivinanza (entretenimiento cortesano y también pastoril, como prueba el Auto pastoril castelhano). Revela al cabo que ha sido testigo de la aparición de la Virgen con el Niño, quien le ha entregado un don destinado a todo el lugar, y le ha confiado un mensaje particular de reconvención para el cura de la parroquia, "que horas nunca lhe rezou / nem dela sóis s'acordou» (vv. 470471). Los pastores y pastoras que le oyen amplifican esta censura, que extienden a otras dignidades eclesiásticas de la comarca, insistiendo sobre todo en su desenfreno sexual e incluyendo el apunte de puniciones ( Bom machado na coroa / que ficasse logo ali. / - Seixo calvo. - Mas setada. / - Arrocho d'azambujeiro. / - Mas pousada de palheiro /e fogo e a porta fechada. / - Mas bom feixe lagariço. / - Penedo. - Trama. Somiço» - vv. 482-489) y remedios («- Vão-se earamá casar / e nam andar de soticapa» - vv. 521-522). Parte Margaída al poblado, para que "os milhores do lugar» (v. 531) organicen la procesión que debe acompañar la entrada del objeto donado por Nuestra Señora. Los demás pastores, impacientes, descubren la imagen de la Virgen envuelta en el haz de leña. Emocionados, mozos y mozas se postran y, dado que ignoran las oraciones de la Iglesia, planean expresar su devoción bailando una chacota: «Pois nam sabemos rezar / façamos-lhe ũa chacota / porque toda a alma devota / o que tem isso há de dar» (vv. 543-546). Sin embargo, su intención se frustra, porque su desencuentro amoroso les impide ponerse de acuerdo para organizar las parejas del baile. Regresa Margaída, acompañada por cuatro clérigos. Superado el escepticismo (cf. v. 585: «Jesu eu estou confuso»), los religiosos rezan "a versos» (i. e., una estrofa cada uno) el himno Ob gloriosa domina, traducido al portugués normativo en solemne métrica de arte mayor y, ahora sí, los pastores y pastoras "ordenam sua chacota» (cuya letra, de tema mariano y natalicio, comienza "Quem é a desposada?»), con la que los actores abandonan el espacio escénico (rúbrica entre los vv. 605 y 606 y rúbrica final). 
Como se comprueba en este resumen, el paralelismo de los títulos Auto pastoril castelhano y Auto pastoril português es en parte engañoso. El regreso de Gil Vicente al drama pastoril navideño a la altura de 1523 se ha efectuado bajo un decidido espíritu de renovación. Ante todo, el dramaturgo remplaza el sayagués y el castellano por el habla rústica portuguesa y el portugués literario. En segundo lugar, prescinde del argumento evangélico, aunque sin desprenderse de su estructura: las réplicas y actitudes pintorescas y ridículas de los pastores en las horas previas al anuncio del Nacimiento dejan paso a la secuencia cómica de los amores rústicos discordantes; la función estructural del mensaje angélico es desempeñada aquí por la revelación de Margaída; la adoración en el pesebre se convierte en la adoración de la imagen de la Virgen con el Niño. En tercer lugar, y gracias a la libertad ganada mediante esa transmutación, el dramaturgo distribuye con plena autonomía los acentos temáticos y los tonos. Así, confirma la tendencia mariana de su devoción navideña, insinuada ya en el Auto pastoril castelhano y bien visible en obras como el Auto da sebila Cassandra. Así también, después de demorarse sin trabas para elaborar hasta el detalle la comedia rústica que fija el registro básico de la representación, gobierna con exquisita sutileza las variaciones de tono iniciadas con la intervención de Margaída y su relato de la aparición sagrada, momento a partir del cual la emoción religiosa va ganando protagonismo, venciendo la resistencia opuesta por motivos anticlimáticos como la sátira del clero desordenado, e incluyendo la preocupación característicamente gilvicentina por las formas de la religiosidad popular y su desconexión de los ritos eclesiásticos normativos.

Debe notarse, por último, que Gil Vicente antepone a la fábula una pieza con función prologal que adopta la forma de introito y argumento definida por Bartolomé de Torres Naharro para sus comedias, impresas en el volumen titulado Propalladia a partir de 1517. Como en las obras del español, el personaje que recita la introducción y, por lo tanto, asume el cometido de mediar entre la realidad y la ficción, es ajeno a la galería de personajes de esta última; más aún, el introductor acentúa su cercanía al auditorio presentándose como ajeno a los actores mismos y a la preparación del juego teatral: él es un hombre común, no un actor, que ha sido encargado por casualidad 
y a última hora de anunciar la escenificación; al mismo tiempo, sin embargo, esta figura que se presenta como real contrasta de modo muy marcado con sus oyentes: su rusticidad no pertenece al mundo de la corte, sino que se ofrece como espectáculo a medias ridículo y a medias provocador (cf. Brotherton, 1975, pp. 96-143). El discurso de Vasco Afonso se divide en las dos partes características del prólogo según Torres Naharro, y repite su movimiento general: en la primera parte, o introito, capta la benevolencia del auditorio por medio de la sorpresa y la hilaridad; en la segunda, o argumento, orienta a ese mismo auditorio hacia el ámbito de la ficción que va a ser escenificada (cf. Surtz, 1979, pp. 129-144), sólo que, en un gesto repetido en las proemios gilvicentinos, evita el resumen anticipatorio y lo substituye por una parodia burlesca.

\subsection{TRAGicomédia DA SERRA DA ESTRELA}

La infanta doña María nace en 1527, mientras la corte reside en Coímbra. Al hilo de esa circunstancia, según señala Costa Pimpão ([s. a.]: p. 3), Gil Vicente contribuye a los regocijos con una segunda obra «em pastoril português». Introduce el espectáculo la propia Sierra de Estrella, «em figura de pastora / feita serrana da Beira» (vv. 8-9), quien, llena de alegría por el feliz acontecimiento, prepara su viaje a palacio, donde quiere ir acompañada por sus «serranas trigueiras / cada qual com seu amigo» (vv. 12-13). Sin embargo, la Sierra de Estrella no ha entrado sola al escenario, sino que ha venido acompañada por un parvo, cuyos disparates ponen el contrapunto burlesco a las expresiones de júbilo franco y entusiasmado.

La Sierra topa con Gonçalo, un pastor que viene de Coímbra, amenizando su camino al compás de la canción que comienza «Volava la pega e vai-se» (vv. 61-segs.). Cuando la Sierra le confía su plan de acudir a palacio acompañada por sus serranas y serranos, Gonçalo le advierte que ello no será posible si no se cumple un requisito previo: "primeiro se hão d'avir / ũa manada d'amores / que nam querem concrudir» (vv. 120-122). El pastor introduce de esta forma el episodio escenificado en la primera parte de la representación, que consiste en una variación sobre el tema del "amor 
louco / eu por ti e tu por outro» ensayado en el Auto pastoril português. Como entonces, Gil Vicente se sirve de tres parejas, pero altera las relaciones. Hay, en primer lugar, un acuerdo familiar de boda entre Gonçalo y Caterina, no deseado por ninguno de los dos jóvenes; Gonçalo quiere a Madanela y Caterina a Fernando, pero Madanela no está dispuesta a casarse con un simple serrano y Fernando corteja en realidad a las tres pastoras. Un tercer mozo, Rodrigo, pretende a Felipa, que aspira a casarse con un cortesano. El acceso de estas seis figuras al espacio escénico es escalonado y, como ocurre en el caso de Gonçalo, ya citado, se acompaña siempre con un canto de tipo tradicional. Los diálogos de las parejas explotan las fuentes de comicidad exploradas en el Auto pastoril português (la parodia rústica de los tópicos y la retórica amorosa de la corte), a las que se suman ahora circunstancias, sentimientos y actitudes ausentes en aquel encadenamiento amoroso: el matrimonio de conveniencia indeseado, el disimulo del pastor inconstante, la fatuidad de las pastoras que desdeñan a los serranos y sueñan con un marido de palacio. Para poder llevar estos desencuentros hacia una concrusão, el dramaturgo hace intervenir a un ermitaño, que llega pidiendo limosna y que recomienda a los jóvenes que se sometan al veredicto de las suertes, por el cual se emparejan Felipa y Rodrigo, Madanela y Fernando, Caterina y Gonçalo. Los seis pastores ponen en fuga al ermitaño, después de que éste haya revelado su hipocresía en una detallada evocación burlesca de su relajado ideal de vida retirada.

Convertida en espectadora durante la secuencia resumida, la Sierra vuelve a ocupar el centro del escenario y prepara con los seis jóvenes la marcha hacia palacio, para agasajar a la infanta recién nacida y a su madre con los frutos y productos de la comarca, clasificados en función de sus poblaciones y evocados en cantidades hiperbólicas, hasta configurar la imagen idealizada de la Sierra de Estrella como cuerno de la abundancia campesina (otra cara del contraste ciudad-campo que late en los motivos pastoriles y villanescos del teatro renacentista y que nutrirá también la comedia española de ambiente rústico, como explica Salomon, 1985, pp. 221-268). Antes de partir, sin embargo, los personajes dichos reciben a Jorge e Lopo, «dous foliões do Sardoal» (rúbrica entre los vv. 644 y 645), que comparecen para animar el epílogo de la obra, concebido como una 
exhibición musical y coreográfica: primero «Canta Lopo e baila arremedando os da serra» (rúbrica entre los vv. 664-665); después los dos foliões cantan y bailan una cantiga "à guisa do Sardoal» (v. 680); por último, los actores abandonan el escenario ordenados en chacota interpretando una cantiga en canto de órgano.

Como puede verse, la Tragicomédia destinada a celebrar el nacimiento de la infanta doña María recupera el esquema del momo de entrega de regalos empleado en la Visitação de 1502 con motivo del nacimiento de don João. El dramaturgo repite también la ambientación pastoril, pero (además de remplazar el castellano y el sayagués por el portugués y su dialecto rústico) enriquece el espectáculo con varios motivos y números (la comedia rústica de amores discordes, la figura burlesca del ermitaño hipócrita, la exhibición coreográfica y musical de los foliões do Sardoal) destinados a convertirlo en una verdadera "festa e regalo dos olhos e dos ouvidos» (Pimpão, [s. a.]: p. 16).

\section{EL PASTOR EN SEGUNDO PLANO}

La mayor parte de las obras comentadas hasta ahora puede calificarse de pastoril, porque en ellas los pastores y su mundo protagonizan la acción o proporcionan la ambientación. Además de ellas, Gil Vicente compuso otras piezas donde recurrió a la materia pastoril como elemento secundario, con diferentes funciones y relevancia. Recordaremos los ejemplos más significativos.

5.1. Tanto en el Auto da Feira como en el Auto da Mofina Mendes, ambos destinados a los maitines de Navidad, la temática pastoril pasa a un segundo plano. El primero, estrenado en 1527, propone la alegoría indicada en el título y muestra una orientación moral y político-religiosa, sirviéndose de Roma como personaje principal, para discutir las causas del controvertido saco acometido ese mismo año por las tropas imperiales. Agotada esta materia, la representación recupera el aire festivo con la intervención cómica de dos parejas de villanos y la participación costumbrista de un grupo de serranas y serranos. El segundo, representado en 1534 según la Copilaçam, pero estre- 
nado quizá en fecha anterior (Révah propone el año 1515) y revisado posteriormente (cf. Brilhante, "Apresentação»), mantiene al fondo el cuadro de los pastores evocados en el Evangelio de Lucas, pero dirige la atención del auditorio hacia el grupo formado por la Virgen María y sus cuatro virtudes personificadas (Pobreza, Humildad, Fe y Prudencia), de acuerdo con el tema aludido en el título original de la obra: Os mistérios da Virgem - cf. v. 99. En el primer cuadro, «será logo o fundamento / tratar da saudadação» (vv. 113114), para lo cual «entra Nossa Senhora vestida como rainha com as ditas donzelas, e diante quatro Anjos com música, e depois de assentadas começam cada ũa d'estudar per seu livro» (rúbrica entre los vv. 132 y 133) las profecías de la Encarnación, sobre todo en lo concerniente a la figura de María, profecías confirmadas por la irrupción del arcángel Gabriel, que abre la escena de la Anunciación. El mismo grupo formado por María y sus cuatro virtudes, al que se añade el personaje de José, protagoniza la secuencia del Nacimiento, que culmina cuando "chora o menino posto em um berço» (rúbrica entre los vv. 670 y 671), y que consiste en una discusión teológico-moral a partir de la interpretación simbólica de las circunstancias que rodean el parto de la Virgen. En relación con esas dos secuencias principales, de contextura alegórica, tono solemne y relieve doctrinal, la materia pastoril desempeña una función de complemento amenizador, en dos momentos. En primer lugar, ocupando el intermedio entre los cuadros de la Anunciación y el Nacimiento. Según indica la rúbrica entre los vv. 314 y 315, «cerra-se a cortina [que delimita el espacio donde se ha escenificado la Anunciación] e ajuntam-se os pastores para o tempo do nacimento». El segmento pastoril comienza y termina con motivos familiares: un zagal se preocupa por la pérdida de un asno y su carga pintoresca, los rústicos se tienden sobre el tablado, vencidos por el sueño; sin embargo, el dramaturgo concede el protagonismo a Mofina Mendes, convirtiendo el segmento en un verdadero entremés centrado en esta singular figura de pastora, cuya fuerza festiva y enigmática transciende el contraste moral con la figura de María, hasta terminar por usurparle el título de la pieza (cf. Resina Rodrigues, 1993, p. 128). Más tarde, los pastores, dormidos sobre el escenario mientras la Virgen, sus virtudes y José interpretaban doctrinalmente el Nacimiento, despiertan para recibir la buena nueva de parte del ángel y cerrar musicalmente la representación. 
5.2. En la cuaresma del año 1534 se escenificó un auto vicentino en el monasterio de Odivelas, sobre el evangelio de la Cananea (Mt 15, 21-28). El Auto da Cananea dramatiza los acontecimientos del relato bíblico y aprovecha el diálogo para extraer sus consecuencias doctrinales, aderezando el conjunto con la ridiculización de las figuras demoníacas, frustradas e impotentes ante el poder de Cristo. La acción principal viene precedida por una introducción que la sitúa en el contexto teológico determinado por la noción de las tres edades de la historia de la humanidad (naturaleza, escritura y gracia) y la idea correlativa de la superación del concepto judaico de Pueblo Elegido por la vocación de universalidad del Cristianismo. Ahora bien, esta introducción adopta la forma de una alegoría pastoril, según anticipa la rúbrica preliminar: "primeiramente, entram três pastoras: a primeira per nome Silvestra lei de natureza, a segunda lei de escritura per nome Hebrea, a tercera lei de graça per nome Veredina» (rúbrica preliminar). Como explica Miller ([s. a.]: pp. 86-87), Gil Vicente da una lección de gracia y destreza, logrando que Silvestra, Hebrea y Veredina causen la impresión de ser verdaderas serranas, al tiempo que sus actitudes y palabras conllevan un segundo sentido que elabora la alegoría en todos sus detalles. Basten dos ejemplos: tanto Silvestra como Veredina abren su recitado con la glosa de un villancico de serrana (que contribuye a la caracterización y ambientación pastoril y, al mismo tiempo, contiene un significado alegórico doctrinal); Hebrea, sin embargo, no puede cantar: su ganado sólo le proporciona disgustos, de modo que, si alguna vez canta, lo hace «super flumina Babilonis» (v. 52); Silvestra y Hebrea, como orgullosas mozas de la sierra, se enzarzan en una discusión sobre sus respectivos méritos, discusión que zanja Veredina cantando «Serranas nam hajais guerra / que eu sam a flor desta serra» (vv. 83-84) y sugiriendo en la glosa respectiva el significado alegórico: la ley de gracia, iniciada con la Encarnación, es la culminación de la historia de la humanidad.

5.3. La Tragicomédia do Inverno e Verão «foi representada ao muito alto e excelente príncipe el rei dom João, o terceiro deste nome em Portugal, na sua cidade de Lixboa, ao parto da devotíssima e muito esclarecida rainha dona Caterina nossa senhora» (rúbrica preliminar), probablemente el primero de mayo de 1529 (Neves, "Apresentação»). La fecha y el motivo explican el concepto 
vicentino, anunciado en el introito: celebrar el nacimiento regio como una primavera, renacimiento de la vida y la alegría que deje atrás la tristeza invernal de los tiempos presentes. El espectáculo se organiza como un díptico que contrapone el triunfo del invierno al triunfo de la primavera, y donde cada una de las partes, presididas por las figuras alegóricas de Invierno, caracterizado como un salvaje, y las de la de Verão y la Sierra de Sintra, presentados como pareja de enamorados, se articula en una serie de episodios autónomos, de contenido y lógica dependientes de la tradición del momo cortesano. En este contexto, y dejando aparte las cuatro parejas sintranas que acompañan el fin del espectáculo cantando y bailando folías, comparecen solamente dos figuras pastoriles, ambas en la primera parte del díptico, respondiendo a los nombres de Brisco Pelayo y Juan Guijarro. Ambos amenizan su recitado con su pintoresco dialecto sayagués y sus cantos rústicos, pero cumplen funciones diferentes. El diálogo de Brisco Pelayo con la figura de Invierno constituye una amplificación desdoblada del monólogo de Invierno en el Auto dos Quatro Tempos, que convoca al pastor como testigo privilegiado de las penalidades padecidas por el ser humano en la fase más hostil del ciclo natural. El papel de Juan Guijarro, que no puede dejar de bailar porque no tiene otro modo de mitigar el frío, al carecer de ropa de abrigo por haber gastado todo su dinero en amoríos durante la primavera pasada, se aparta de todo realismo y presenta un valor cómico que prepara el simbolismo burlesco y naturalista de la siguiente figura: la vieja dispuesta a cruzar descalza la sierra cubierta de nieve a cambio de satisfacer su deseo de casarse. De todas formas, no debe olvidarse la interpretación de Gerhardt (1975, pp. 146-152), quien, más allá de estas figuras concretas de pastores, descubre en los personajes mayores de la Tragicomédia, Invierno, Verão y Sierra de Sintra, la expresión plena del sentimiento de la naturaleza gilvicentino, subyacente a todo su teatro pastoril, formulado aquí mediante un procedimiento simbólico ensayado en el Auto dos Quatro Tempos.

\section{Pastores y villanos}

6.1. La exploración del tipo del pastor, inicialmente heredado del teatro primitivo salmantino, condujo pronto a Gil Vicente al descubrimiento 
de tipos afines, bien por la ambientación, bien por el carácter, con la intención de modular de manera más eficaz los efectos burlescos y satíricos, los tonos realistas y fantásticos. En consecuencia, y como señala Miller ([s. a.]: pp. 69-71), el estudio de la figura del pastor en nuestro dramaturgo no puede separarse limpiamente de la valoración de otras figuras, en especial la del villano y la del parvo, metamorfosis del rústico que anticipan los desarrollos que originarían, en el teatro peninsular, los personajes del campesino y del simple. Este último resulta de la simplificación de la figura del pastor, en los dos sentidos de la palabra: estilización reductora del personaje y limitación a una de sus facetas, la de simple, núcleo de una caracterización que lo presenta como muchacho, casi siempre criado perezoso y torpe, bautizado con el nombre proverbial del bobo, Joane. En esencia, Gil Vicente anticipa con el personaje del parvo la evolución general del tipo del pastor en el teatro peninsular del siglo XVI, que tiende a disolverlo en la figura cómica del necio (cf. Brotherton, 1975, pp. 144-195).

6.2. No cabe olvidar tampoco que Gil Vicente acoge también en su teatro el motivo del caballero disfrazado de rústico por amor. Lo hace en la Comédia do Viuvo (1514), donde don Rosvel alterna dos registros en su simulación: el cómico, propio del rústico grosero, cuando finge ante el padre viudo; el lírico, propio del pastor sentimental, cuando lo hace ante las hijas. Ambos registros se separan en la Tragicomédia de Dom Duardos (1521-1525), asumiendo el primero la familia de hortelanos y el segundo el propio caballero de incógnito. El motivo, de procedencia novelesca, fue trasladado al teatro por Gil Vicente y Torres Naharro (Comedia Aquilana) e hizo fortuna sobre las tablas, en buena medida gracias a la posibilidad de combinar los dos registros mencionados, el cómico y el sentimental, en favor de la variedad de efectos escénicos?

9 La Comedia Aquilana no se incluyó en la colección de Bartolomé de Torres Naharro, titulada Propalladia, hasta la tercera edición (Nápoles, 1524). Se conservan ejemplares de una impresión suelta, sin lugar ni fecha. Cf. López Morales, 1986, pp. 16-17 y 90-91. Sobre la influencia convergente de esta comedia naharresca y la Tragicomédia de Don Duardos, cf. Rodríguez Rodríguez, 2003. 
6.3. Con ocasión de Purgatório nos hemos referido ya a las similitudes y diferencias de villanos y pastores. En general, el villano representa una categoría social más amplia y menos condicionada por la tradición teatral y literaria, susceptible por ello de producir un mayor efecto de realismo. La Tragicomédia Romagem dos Agravados (representada en palacio en 1533, para festejar el nacimiento del infante don Felipe) ofrece otra buena muestra de la continuidad y el contraste entre pastores y villanos. El personaje burlesco de Frei Paço, que recita el introito y actúa como mediador entre los personajes de ficción y el auditorio cortesano, interroga a una serie de figuras que compone la romería de agraviados aludida en el título. La primera de ellas responde al nombre de João Mortinheira, un labrador frustrado por el escaso fruto obtenido de su trabajo incesante, a causa de las contrariedades del clima. Considerando a Dios responsable de su desgracia, ha abandonado la oración y ha dejado de cumplir con el diezmo. Frei Paço le reconviene por ello y le aconseja que se resigne a la inescrutable voluntad divina. Con todo, João Mortinheira quiere que su hijo Bastião escape a la dureza de la vida campesina convirtiéndose en hombre de iglesia; el segmento final del episodio escenifica el número hilarante de la instrucción imposible del mozo rústico, incapaz de asimilar el alfabeto o de distinguir las palabras «amém» y «abém» (vv. 186-189). Después del desfile de una pareja de hidalgos enamorados, otra de regateiras engañadas y otra formada por un cortesano y un eclesiástico ambiciosos hasta la desmesura, llega el segundo labrador, de nombre Apariç'Eanes, quejoso de su pobreza, y especialmente de la opresión que sufre de parte de unos codiciosos frailes cuyas fincas cultiva. Desea librar de la miserable vida campesina a su hija Giralda, introduciéndola en palacio, de manera que el resto del episodio representa los números burlescos de la educación cortesana de la moza campesina y la insinuación galante de frei Paço. Como se ve, ambos episodios villanescos tienen una segunda parte francamente cómica, pero en ambos casos hay un segmento primero y principal que justifica la advertencia de la rúbrica preliminar: «Esta tragicomédia [...] é sátira», y donde la vena crítica se sustenta en la evocación realista de las condiciones de vida del labrador. La relación entre estos ingredientes se invierte en el caso de las últimas figuras de la romería, Juliana e Hilária, pastoras, cuya única preocupación es de índole amorosa y consiste en que los matrimonios concertados para ellas no coinciden con sus deseos; estos 
personajes no conducen nuestra imaginación hacia la realidad, sino hacia la literatura y el teatro (recuérdese la Tragicomédia da Serra da Estrela), y el agravio de que se quejan no ofrece un rendimiento crítico o satírico, sino puramente cómico. Con todo, esta distinción entre las figuras villanescas (de carácter más realista y de efecto satírico) y las pastoriles (de carácter literario y de efecto cómico) no anula la afinidad entre unas y otras, como muestra la naturalidad con que las zagalas solicitan la compañía protectora del labrador João Mortinheira y el conocimiento de causa con que éste se explaya a propósito de las «cachopas» (v. 981).

6.4. Por otro lado, el tipo del villano puede recibir un tratamiento puramente burlesco, según ilustra de forma eminente el caso de Pero Marques. En la Farsa de Inês Pereira (1523), se identifica con la bestia de carga del refrán "Mais quero asno que me leve que cavalo que me derrube»: sufre, primero, el desprecio de la Inês soltera y fantasiosa; y se convierte, a la postre, en víctima de la Inês viuda y desengañada, que se casa con el inocente rústico para resarcirse del encierro a que la ha tenido condenada su primer marido, el hidalgo, concibiendo de inmediato planes de adulterio. En la Farsa do Juiz da Beira (1525), Pero Marques mantiene intacta su incultura absoluta. Ahora bien, beneficiándose del privilegio concedido a veces a la figura burlesca del simple, más cercano a la verdad o mejor protegido frente al engaño que los cuerdos y los letrados (cf. Brotherton, 1975, pp. 63-94), y anticipando las sentencias de Sancho Panza en la Ínsula Barataria y todo un filón del entremés del siglo XVII, el juez de la Beira llamado a Lisboa para probar su competencia se toma cierta revancha frente al prejuicio cortesano al provocar nuestra risa no sólo como objeto, sino también como sujeto: reímos, en efecto, de su rudeza y sus disparates, pero también lo hacemos de los errores y desatinos insospechados de los personajes urbanos que aquellos ponen sorprendentemente al descubierto.

A modo de epílogo, debe recordarse que Gil Vicente inicia su carrera teatral bajo la influencia de la espectacularidad cortesana y el teatro inci- 
piente de los salmantinos, donde el pastor ocupaba un lugar privilegiado: no sólo era el verdadero protagonista de las representaciones navideñas en boga, que seguían el esquema del officium pastorum, sino que proporcionaba escenificaciones puramente profanas, partiendo del asunto de la pastorela, o bien de la simple exhibición de su carácter exótico y ridículo. De hecho, la confluencia de tradiciones que se producía a comienzos del siglo XVI en la figura del pastor (la lectura de Virgilio en la escuela medieval, los géneros líricos culto y popular de la pastorela y los cantos de serrana, la bucólica medieval de orientación alegórica y didáctica con sus prolongaciones renacentistas, la nueva bucólica amorosa italiana) le proporcionaba una ductilidad única, que le permitió convertirse durante varias décadas en el tipo teatral por excelencia, una suerte de máscara que, al margen de tramas y caracterizaciones particulares, funcionaba como indicio de teatralidad, como signo diferenciador del nuevo arte de la escena frente al magma originario de la espectacularidad festiva.

Gil Vicente adoptó la figura y contribuyó a su consolidación como síntoma del fenómeno teatral. Exploró casi todas sus posibilidades (con la excepción del tratamiento refinado y sentimental de la nueva bucólica amorosa italiana), llevando algunas a su perfección (según señala Gerhardt, 1975, a propósito de la comedia de amores rústicos integrada en el Auto da sebila Cassandra), animado siempre por su característico afán de variedad. En este sentido, cabe destacar dos ejemplos de diversa índole: por un lado, los repetidos y diferenciados experimentos de combinación de la materia pastoril y la alegoría; por otro, la adaptación del modelo rústico del teatro castellano primitivo al contexto portugués, con la elaboración de un dialecto rústico lusitano que naturalizara el efecto cómico y caracterizador del sayagués usado por los maestros salmantinos.

No obstante, el reiterado y variado recurso al tipo del pastor no oculta cierta insatisfacción en el dramaturgo, causada precisamente por el factor arriba aducido para explicar su éxito en el primer teatro moderno peninsular: Gil Vicente ha debido sentirse limitado en exceso por el condicionamiento y resonancias literarias de la figura y ha pretendido liberarse acompañándola o remplazándola por un tipo afín pero diferente, el tipo del villano, que podía moldear con casi completa autonomía para adaptarlo en cada obra y 
en cada paso a su libre vaivén entre la sátira y la burla, la realidad y la fantasía, la observación crítica y la explosión festiva.

\section{BIBLIOGRAFÍA CITADA}

Asensio, Eugenio (1974), «El Auto dos Quatro Tempos de Gil Vicente» (1949), en Estudios portugueses, París, Fundação Calouste Gulbenkian - Centro Cultural Portugués, pp. 79-101.

- (1974), "Las fuentes de las Barcas de Gil Vicente. Lógica intelectual e imaginación dramática» (1953), en Estudios portugueses, París, Fundação Calouste Gulbenkian — Centro Cultural Portugués, pp. 59-77.

Brilhante, M. ${ }^{a}$ J., "Apresentação» de Gil Vicente, Auto de Mofina Mendes, en Centro de Estudos de Teatro, Teatro de Autores Portugueses do Séc. XVI — base de dados textual on-line (http:// www.cet-e-quinhentos.com/) [20/07/2013].

Brotherton, J. (1975), The "pastor-bobo" in the Spanish theatre befor the time of Lope de Vega, London, Tamesis Books Limited.

Busnardo-Neto, JoAnne McCaffrey (1974), The Eclogue in Sixteenth Century Portugal, The University of Michigan.

Calderón, M. (1996), La lírica de tipo tradicional de Gil Vicente, Alcalá de Henares, Universidad de Alcalá de Henares.

Calderón de la Barca, Pedro (2010), La vida es sueño, ed. E. Rodríguez Cuadros, Madrid, EspasaCalpe.

Centro de Estudos de Teatro, Teatro de Autores Portugueses do Séc. XVI — base de dados textual on-line (http://www.cet-e-quinhentos.com/) [20/07/2013].

Costa Pimpão, Álvaro Julio da [s. a.], «Introdução», en Gil Vicente, Tragicomédia pastoril da Serra da Estrêla, ed. A. J. da Costa Pimpão, Coimbra, Coimbra Editora, pp. 1-29.

Enzina, Juan del (1983), Obras completas. IV: Teatro, ed. A. M. ${ }^{a}$ Rambaldo, Madrid, Espasa-Calpe.

Gerhardt, M. I. (1975), Essai d'analyse littéraire de la pastorale dans les littératures italienne, espagnole et française, Assen, 1950; reimpresión, Utrecht, H\&S.

Gouveia, C., "Apresentação» de Gil Vicente, Auto da Fe, en Teatro de Autores Portugueses do Séc. XVI — base de dados textual on-line (http://www.cet-e-quinhentos.com/) [20/07/2013].

Grande Quejigo, F. J. (2004), "Tradición e innovación en el teatro litúrgico de Gil Vicente», en M. ${ }^{a}$ J. Fernández García y A. J. Pociña López, coors., Gil Vicente: clásico luso-español, Mérida, Editora Regional de Extremadura, pp. 35-57.

Laitenberger, H. (1991), "Gil Vicente, dramaturgo navideño", en J. Canavaggio y B. Darbord, eds., Edad Media y Renacimiento. Continuidades y rupturas, Caen, Centre de Publications de l'Université de Caen, pp. 65-87.

Lida de Malkiel, M. ${ }^{a}$ R. (1966), "Para la génesis del Auto de la sibila Casandra» (1959), en Estudios de literatura española y comparada, Buenos Aires, EUDEBA, pp. 157-172.

López Morales, H. (1986), «Estudio preliminar», en Bartolomé de Torres Naharro, Comedias, ed. H. López Morales, Madrid, Taurus, pp. 7-98.

Manrique, Gómez (2003), Cancionero, ed. F. Vidal González, Madrid, Cátedra.

Miller, N. [s. a.], O Elemento Pastoril no Teatro de Gil Vicente, Porto, Editorial Inova.

Montemayor, Jorge de (1991), La Diana, ed. A. Rallo, Madrid, Cátedra. 
Neves, L. C., "Apresentação» de Gil Vicente, Tragicomédia de Inverno e Verão, en Centro de Estudos de Teatro, Teatro de Autores Portugueses do Séc. XVI — base de dados textual on-line (http:// www.cet-e-quinhentos.com/) [20/07/2013].

Révah, I. S. (1959), «L’Auto de la Sibylle Cassandre de Gil Vicente», Hispanic Review, XXVII, pp. 167-193. Rodrigues, M. ${ }^{a}$ Idalina Resina (1993), "Dos salmantinos a Gil Vicente: As celebrações do Natal», en Actas do IV Congresso da Associação Hispânica de Literatura Medieval (Lisboa, 1-5 Outubro 1991), ed. A. A. Nascimento e C. A. Ribeiro, Lisboa, Edições Cosmos, vol. I, pp. 107-135.

Rodríguez Rodríguez, J. J. (2003), "Introducción», en Auto do duque de Florença, ed. J. J. Rodríguez Rodríguez, Bilbao, UPV-EHU, pp. 11-39.

Salomon, N. (1985), Lo villano en el teatro del Siglo de Oro (1965), Madrid, Castalia.

Serôdio, C., "Apresentação" de Gil Vicente, Auto da Fama, en Centro de Estudos de Teatro, Teatro de Autores Portugueses do Séc. XVI - base de dados textual on-line (http://www.cet-e-quinhentos.com/) [20/07/2013].

Shergold, N. D. (1967), A History of the Spanish Stage from Medieval Times until the End of the Seventeenth Century, Oxford, Clarendon Press.

Surtz, R. E. (1979), The Birth of a Theater. Dramatic Convention in the Spanish Theater from Juan del Encina to Lope de Vega, Madrid/Princeton, Castalia/Princeton University.

Teyssier, P. (1959), La langue de Gil Vicente, París, Librairie C. Klincksieck.

Wardropper, B. W. (1967), Introducción al teatro religioso del Siglo de Oro, Madrid, Revista de Occidente, 1953. 2. ${ }^{\text {a }}$ ed., Salamanca, Anaya. 